\title{
Functional Associations of Temperamental Predisposition and Brain Responses While Processing Stressful Word Stimuli Related to Interpersonal Relationships in Bulimia Nervosa Patients: an fMRI Study
}

\author{
Yoshie Miyake $^{1^{*}}$, Yasumasa Okamoto ${ }^{2}$, Keiichi Onoda ${ }^{3}$, Yuri Okamoto ${ }^{1}$ and Shigeto Yamawaki ${ }^{2}$ \\ ${ }^{1}$ Health Service Center, Hiroshima University, 1-7-1, Kagamiyama, Higashi-Hiroshima, 739-8514, Japan \\ ${ }^{2}$ Department of Psychiatry and Neurosciences, Division of Frontier Graduate School of Biomedical Sciences, Hiroshima University, \\ 1-2-3, Kasumi, Minami-ku, Hiroshima, 734-8551, Japan \\ ${ }^{3}$ Department of Neurology, Shimane University, 89-1, Enya-cho, Izumo, Shimane, 693-8501, Japan
}

\author{
Correspondence to: \\ Yoshie Miyake \\ Health Service Center, \\ Hiroshima University 1-7-1, Kagamiyama \\ Higashi-Hiroshima, 739-8514, Japan \\ Tel: +81-82-424-6186 \\ Fax: +81-82-424-6178 \\ E-mail: miyakechare@hiroshima-u.ac.jp
}

Received: March 08, 2016

Accepted: May 19, 2016

Published: May 20, 2016

Citation: Miyake Y, Okamoto Y, Onoda K, Okamoto Y, Yamawaki S. 2016. Functional Associations of Temperamental Predisposition and Brain Responses While Processing Stressful Word Stimuli Related to Interpersonal Relationships in Bulimia Nervosa Patients: an fMRI Study. J Neuroimaging Psychiatry Neurol 1(1): 46-53.

Copyright: ( 2016 Miyake et al. This is an Open Access article distributed under the terms of the Creative Commons Attribution 4.0 International License (CC-BY) (http://creativecommons. org/licenses/by/4.0/) which permits commercial use, including reproduction, adaptation, and distribution of the article provided the original author and source are credited.

Published by United Scientific Group

\begin{abstract}
Bulimia nervosa (BN) is characterized by frequent episodes of uncontrolled overeating and difficulties in adapting to stressful situations. BN patients tend to be sensitive to frustration and impulsive. Personality traits may be associated with the abilities of $\mathrm{BN}$ patients to adapt to stressful situations, especially in interpersonal relationships. The aim of the present study was to investigate the functional abnormalities in various brain systems while processing stressful word stimuli related to interpersonal relationships in $\mathrm{BN}$ patients. Functional magnetic resonance imaging was used to examine the brain responses of $15 \mathrm{BN}$ patients and 20 healthy women while processing unpleasant words related to interpersonal relationships. We also investigated the relationships between brain responses and temperament trait scale from the Temperament and Character Inventory. BN patients showed significant activations of medial prefrontal cortex and anterior cingulate cortex (ACC) while processing these words. ACC activation was significantly greater in $\mathrm{BN}$ patients than in healthy women. Among $\mathrm{BN}$ patients, the score of the harm avoidance was positively correlated with the activation of the ACC, and the score of the novelty seeking was negatively correlated with the activations in the left inferior frontal gyrus (IFC) and the insula. These results suggest that ACC activation may play crucial roles in emotional processing impairments of BN. Reduced activations of IFC and insula while processing stressful words may reflect a general failure of self-regulation. These abnormal functional responses to stressful stimuli may be involved in difficulties in adapting to stressful situations in $\mathrm{BN}$ patients.
\end{abstract}

\section{Keywords}

fMRI, Eating disorders, Bulimia nervosa, Interpersonal relationship stress, Temperament traits

\section{Introduction}

Eating disorders (EDs) are an important cause of physical and psychosocial morbidity in young women. EDs are classified primarily into two major categories; anorexia nervosa (AN) and bulimia nervosa $(\mathrm{BN})$. Bulimia nervosa $(\mathrm{BN})$ is characterized by frequent episodes of uncontrolled overeating. $\mathrm{BN}$ patients tend to recover from stress slowly. Peterson et al. [1] reported that stress reactivity appears to be especially important for understanding and treating BN. The psychological stressors around us include interpersonal conflicts and isolation [2]. Difficulties in adapting to stressful situations might play a role in the development of the disorders associated with BN. Cognitive theories of eating disorders (EDs) 
include a role for distorted beliefs about the self with content that is ostensibly unconnected to weight, shape or eating $[3,4]$. A recent study of $\mathrm{BN}$ reported that self-referent emotional information reduced neural activation in the parietal, occipital and limbic areas in $\mathrm{BN}$ patients compared to controls [4].

$\mathrm{BN}$ patients tend to be impulsive and show disinhibited personality characteristics $[5,6]$. Several studies have reported that ED patients differ from healthy controls in reward and punishment sensitivity as measured with the Temperament and Character Inventory (TCI) [7, 8]. The TCI has been used previously to deepen our understanding of the personality traits of ED patients and to allow for correlational inferences based on neurophysiologic, therapeutic and prognostic perspectives [9]. Some studies have shown that ED is commonly related to specific personality traits and particularly elevated harm avoidance (HA) $[10,11]$. Temperamental data have revealed that high novelty seeking (NS) represents a specific genetic predisposition to binge-purging behaviors when other predisposing factors to ED coexist [11-13]. Temperamental traits are potentially associated with specific genetic and biological substrates that are relatively consistent and stable over time $[14,15]$. They are said to be heritable, stable across time and dependent on genetic and neurobiological factors [16]. Amianto et al. [17] reported that anger mediation between cooperativeness, and binge eating and impulsive behaviors confirm the relevance of relational dynamics in the expression of these core eating symptoms in $\mathrm{BN}$ patients. Personality traits may influence or be associated with the abilities of BN patients to adapt to stressful situations and manage their disease. Recent relevant biological studies have reported significant associations between various dimensions of temperament and brain activity based on Cloninger's model. Gardini et al. [16] suggested that individual differences in the temperament dimensions might reflect structural variance in specific brain areas. Youn et al. [18] reported that NS is primarily correlated with the activities of the substantia nigra and several temporal regions and that HA and reward dependence $(\mathrm{RD})$ were primarily correlated with the activities of the temporal lobe and orbitofrontal gyrus in a positron emission tomography (PET) study. One functional magnetic resonance imaging (fMRI) study demonstrated that blood oxygen level dependent (BOLD) signals are correlated with scores on various personality scales, and these signals suggest that variations in personality traits might partially account for variations in the neural responses of particular brain regions [19]. Neurobiological vulnerabilities have been implicated in the pathogenesis of ED [8]. Marsh et al. [20] reported that general self-regulatory functions demonstrated impulsive response on a behavioral level and front striatal dysfunction in BN. Understanding how the abnormalities in brain function that are related to personality traits might cause or maintain BN may lead to more successful interventions for $\mathrm{BN}$. However, there is little data regarding the brain functions associated with the temperamental predisposition in $\mathrm{BN}$ patients.

The purpose of the present study was to investigate the relationships between functional abnormalities and temperament trait scale scores from the TCI in $\mathrm{BN}$ patients during the processing of stressful words related to interpersonal relationships in an fMRI experiment. Our previous research found that the left medial prefrontal cortex (mPFC) of $\mathrm{BN}$ patients were significantly activated in response to negative body-image words and suggested that the $\mathrm{mPFC}$ is associated with the functional abnormalities of brain systems in $\mathrm{BN}$ patients [21]. Joos et al. [22] substantiates a key role of lateral prefrontal dysfunction, which is a brain region involved in impulsive control, in $\mathrm{BN}$ patients. The binge eating/purging group showed significantly greater activations of the bilateral precentral gyrus, anterior cingulated cortex (ACC), and middle and superior temporal gyrus than healthy groups during a response inhibition task [23]. In the present study, we hypothesized that the $\mathrm{BN}$ patients would show prefrontal cortex (PFC) and ACC activations that are associated with the aspects of temperament that are specific to $\mathrm{BN}$.

\section{Materials and Methods}

\section{Participants}

Fifteen BN patients were recruited from a pool of outpatients. For the comparison with $\mathrm{BN}$ patients, twenty healthy women were recruited via a community announcement. The exclusion criteria for the study were the presence of metallic implants, claustrophobia, and the presence of any Axis I or II psychiatric diagnosis other than BN. The Structured Clinical Interviews for DSM-IV Axis I and II Disorders $[24,25]$ were conducted with all of the participants. The healthy women participated in our previous study [26]. All patients fulfilled the DSM-IV diagnostic criteria for BN. Additionally, at least two senior psychiatrists interviewed the patients to ensure that the diagnoses were accurate. Three of the patients were taking antidepressant medication. All participants were right-handed Japanese women. Handedness was determined using the Edinburgh Handedness Inventory [27]. The clinical characteristics of the participants were averaged, and the group comparison was made by using a $t$ test. The study was conducted according to a protocol approved by the ethics committee of the Hiroshima University School of Medicine. All participants provided written informed consent prior to their participation.

\section{Psychological assessment}

The psychological assessments of all of the participants were conducted prior to scanning. The four temperament scales of the Japanese-version of the TCI [28] were used to assess temperament. We also used the Japanese version of the Eating Disorders Inventory-2 (EDI-2) [29] to further examine our participants' eating problems.

\section{Stimuli and task}

We used the emotional decision-making task developed by Shirao et al. [30]. For our study, 30 unpleasant words related to interpersonal relationships were chosen from Japanese-language dictionaries/thesauri. Thirty neutral words were selected from the database of Toglia and Battig [31] and translated into Japanese (Figure 1a). The unpleasant words and neutral words did not significantly differ with regard to word length nor familiarity [32]. The selected words were used 
to generate three-word sets of unpleasant words related to interpersonal relationships (for example, 'contempt', 'betrayal' and 'disappointment') and sets of neutral words (for example, 'center', 'region' and 'moment'). Each word set comprised a unique combination of three words. The word sets were presented in six alternating blocks across two conditions (task and control conditions) in three cycles (Figure 1b). The unpleasant word sets were presented during the task condition, and the neutral word sets were presented during the control condition. Each block began with a 3 s cue that identified the condition (the word 'task' or 'control'). Five word sets were presented in each block. Each word set was shown for $4 \mathrm{~s}$, with a $1.4 \mathrm{~s}$ interstimulus interval (Figure 1c). The BOLD responses were recorded during the six blocks of each word task. A fixation cross appeared at the center of the screen during each interstimulus interval. In the task condition, the participants were instructed to select the most unpleasant word from each word set based on their personal knowledge and experience; in the control condition, they were instructed to select the most neutral word from each word set. The participants indicated their choices by pressing one of three buttons on a response pad in the MRI scanner.

(a)

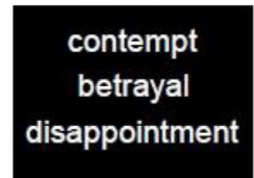

(b)

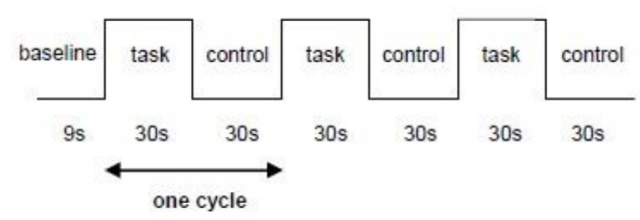

(c)

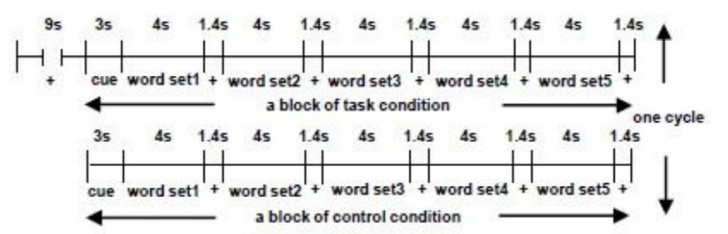

Figure 1: Design of the study task.

\section{Evaluation of the unpleasantness and familiarity of the word stimuli}

Each participant was asked to rate the unpleasantness and familiarity of all of the words presented during the experiment on scales that range from 1 (very unpleasant; very unfamiliar) to 7 (very pleasant; very familiar). These ratings were obtained immediately after scanning to investigate the task manipulation of emotionality. The words were presented in a randomized order in a table format after scanning. The subjective ratings were averaged for each category of words.

\section{Image acquisition}

The fMRI scans were performed using a Magnetom
Symphony Maestro Class MRI scanner (Siemens, Tokyo, Japan; 1.5 Tesla). A time-course series of 63 volumes was acquired during the task with $\mathrm{T} 2{ }^{*}$-weighted, gradient echo, echo planar imaging (EPI). Each volume encompassed the entire brain and consisted of 28 axial slices, and the slice thickness was $4.0 \mathrm{~mm}$ with no gap. The interval between two successive acquisitions of the same image (TR) was $3000 \mathrm{~ms}$, the echo time (TE) was $55 \mathrm{~ms}$ and the flip angle was $90^{\circ}$. The field of view (FOV) was $256 \mathrm{~mm}$ and the matrix size was $64 \times$ 64 , which produced a voxel dimension of $4.0 \times 4.0 \times 4.0 \mathrm{~mm}$. After functional scanning, structural scans were acquired using a T1-weighted gradient echo pulse sequence $(\mathrm{TR}=12 \mathrm{~ms}$; TE $=4.5 \mathrm{~ms} ;$ Flip angle $=20^{\circ} ; \mathrm{FOV}=256 \mathrm{~mm}$; voxel dimensions of $1.0 \times 1.0 \times 1.0 \mathrm{~mm}$ ) to facilitate localization.

\section{fMRI analysis}

The image processing and statistical analyses were performed using the Statistical Parametric Mapping 5 (SPM5) software (Wellcome Department of Cognitive Neurology, London, UK), implemented in Matlab (Mathworks, Inc., Natick, MA). The first two volumes of each fMRI run were discarded to allow for stabilization of the magnetization. Each set of functional volumes was realigned to the first volumes, spatially normalized to a standard template based upon the Montreal Neurological Institute (MNI) reference brain, and finally smoothed using a $12-\mathrm{mm}$ full-width, half-maximum Gaussian filter. We conducted group analyses according to a random effect model that permitted inferences to the general population [33]. We first identified brain regions that showed significant responses during the task condition compared with the control condition in each group. Next, we performed a two-sample $t$-test to identify group differences. The data were considered significant at a threshold of $p<0.001$ that was uncorrected at the voxel level if the voxels belonged to a cluster of activation with an extent of at least 10 voxels. For the BN patients, the images were entered into a regression analysis to identify the brain regions in which the magnitudes of brain activation were significantly correlated with the scores on the temperament dimensions of the TCI and the subjective ratings of the words. To test for region-specific covariate effects, the estimates were compared using two linear contrasts (positive or negative correlations). The data were considered significant at a threshold of $\mathrm{p}<0.001$ that was uncorrected at the voxel level.

\section{Results}

\section{Participant characteristics}

As shown in Table 1, the average TCI scores of the BN patient for NS, HA, RD, and PT were 50.8 (range: 43-63), 63.2 (range: 47-78), 40.8 (range: 28-50), and 11.4 (range: 7-14), respectively. The average TCI scores of the control subjects for NS, HA, RD, and PT were 47.4 (range: 34-59), 53.4 (range: 32-67), 45.0 (range: $35-54$ ), and 13.2 (range: 11-17). Our BN patients exhibited significantly higher HA and lower RD and PT scores than the control subjects. The BN patients scored significantly higher on all of the subscales of the EDI-2 than the control subjects. No temperament scores or EDI-2 scores were significantly correlated with the participants' ages or body mass index (BMI). 
The ratings of familiarity for the two categories of words did not differ significantly between the BN patients (mean familiarity score for interpersonal relationship words $=4.3$ and neutral words $=4.2$ ) and the control subjects (mean familiarity score for interpersonal relationship words $=4.5$ and neutral words $=4.6$ ). However, all of the participants rated the interpersonal relationship words to be significantly more unpleasant than the neutral words (mean unpleasantness scores for the interpersonal relationship words $=1.9$ and neutral words $=3.9, \mathrm{p}<0.001$ in the $\mathrm{BN}$ patients; mean unpleasantness scores for the interpersonal relationship words $=2.1$ and neutral words $=4.0, \mathrm{p}<0.001$ in the control subjects). Neither the ratings of unpleasantness nor the ratings of familiarity within each word category differed significantly between the $\mathrm{BN}$ patients and the control subjects.

Table 1: Clinical characteristics of the participants.

\begin{tabular}{|c|c|c|c|c|}
\hline & $\mathrm{BN}$ patients & Control & \multirow{2}{*}{$\mathbf{t}$} & \multirow{2}{*}{$\mathbf{p}$} \\
\hline & $(n=15)$ & $(\mathrm{n}=20)$ & & \\
\hline Age (years) & $26.1 \pm 7.2$ & $25.6 \pm 4.6$ & 0.24 & 0.805 \\
\hline Body mass index $\left(\mathrm{kg} / \mathrm{m}^{2}\right)$ & $22.1 \pm 4.4$ & $19.3 \pm 1.9$ & 2.31 & $<0.05$ \\
\hline Education (years) & $13.8 \pm 1.4$ & $15.6 \pm 1.5$ & 3.92 & $<0.001$ \\
\hline Duration of BN (years) & $5.6 \pm 4.2$ & & & \\
\hline \multicolumn{5}{|c|}{ Temperament and Character Inventory } \\
\hline Novelty seeking & $50.8 \pm 5.9$ & $47.4 \pm 7.1$ & 1.47 & 0.15 \\
\hline Harm avoidance & $63.2 \pm 8.2$ & $53.4 \pm 9.5$ & 3.14 & $<0.01$ \\
\hline Reward dependence & $40.8 \pm 5.8$ & $45.0 \pm 5.3$ & 2.14 & $<0.05$ \\
\hline Persistence & $11.4 \pm 2.1$ & $13.2 \pm 1.9$ & 2.40 & $<0.05$ \\
\hline Self-directedness & $50.1 \pm 8.3$ & $69.2 \pm 10.5$ & 5.73 & $<0.001$ \\
\hline Cooperativeness & $70.8 \pm 7.0$ & $76.4 \pm 5.0$ & 2.70 & $<0.05$ \\
\hline Self-transcendence & $27.1 \pm 5.9$ & $29.5 \pm 8.0$ & 0.95 & 0.34 \\
\hline \multicolumn{5}{|c|}{ Eating Disorder Inventory-2 } \\
\hline Total score & $126.2 \pm 44.8$ & $33.2 \pm 14.9$ & 7.72 & $<0.001$ \\
\hline Drive for thinness & $14.7 \pm 4.0$ & $2.9 \pm 4.1$ & 8.37 & $<0.001$ \\
\hline Bulimia & $12.3 \pm 5.7$ & $1.0 \pm 1.4$ & 7.40 & $<0.001$ \\
\hline Body dissatisfaction & $18.5 \pm 6.8$ & $8.5 \pm 5.4$ & 4.80 & $<0.001$ \\
\hline Ineffectiveness & $16.1 \pm 6.6$ & $4.6 \pm 3.4$ & 6.17 & $<0.001$ \\
\hline Perfectionism & $6.4 \pm 3.6$ & $1.6 \pm 1.5$ & 4.77 & $<0.001$ \\
\hline Interpersonal distrust & $8.3 \pm 4.2$ & $3.3 \pm 2.9$ & 4.04 & $<0.001$ \\
\hline Interoceptive awareness & $12.7 \pm 7.6$ & $0.7 \pm 1.2$ & 5.90 & $<0.001$ \\
\hline Maturity fears & $9.4 \pm 6.4$ & $3.3 \pm 2.7$ & 3.40 & $<0.01$ \\
\hline Ascetism & $8.0 \pm 4.6$ & $1.9 \pm 1.1$ & 4.93 & $<0.001$ \\
\hline Impulse regulation & $8.9 \pm 6.0$ & $0.4 \pm 0.8$ & 5.43 & $<0.001$ \\
\hline Social insecurity & $10.9 \pm 4.0$ & $4.8 \pm 3.4$ & 4.68 & $<0.001$ \\
\hline
\end{tabular}

Results are shown as the mean \pm the standard deviation.

$\mathrm{BN}=$ bulimia nervosa $\mathrm{t}=$ test value; $\mathrm{p}=\mathrm{p}$-value.

\section{fMRI results}

\section{Brain activation during the task}

Compared to the control task, the interpersonalrelationship word task condition resulted in significant activations of the $\mathrm{mPFC}$ and the left ACC (Brodmann area: $\mathrm{BA} 10$ ) in the $\mathrm{BN}$ patients (Figure 2a and Table 2). No significant activations were found in the control subjects. The activations in the right $\mathrm{mPFC}(\mathrm{BA} 9,10)$, the $\mathrm{ACC}(\mathrm{BA} 9,32)$ and the left parietal lobule (BA 7) were significantly greater in the $\mathrm{BN}$ patients than in the control subjects during the task (Figure $2 \mathrm{~b}$ and Table 2). No temperament scores or the subjective ratings of the words were significantly correlated with the activations of these areas. No brain area exhibited significantly greater activation in the control subjects than in the $\mathrm{BN}$ patients.

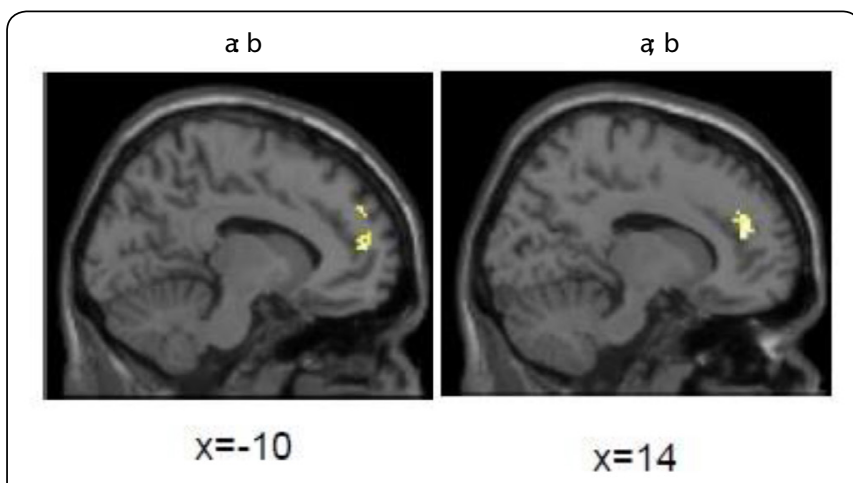

Figure 2: Brain activations during the task in the BN patients. (a) Brain activation during the task. (b) Group comparison.

Table 2: Areas with significant activation during the task condition compared to the control condition.

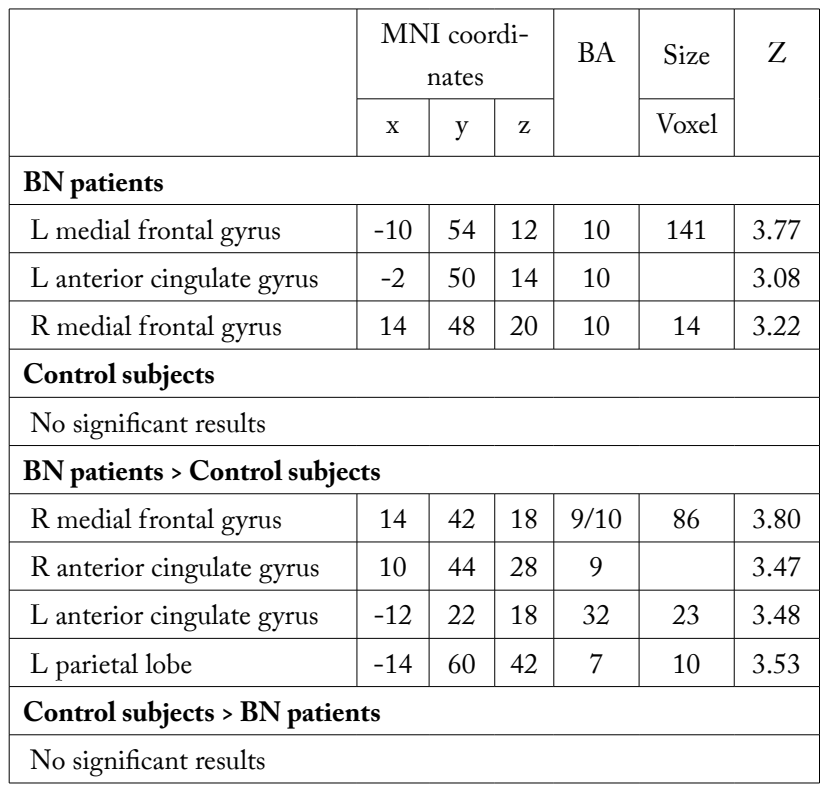

All areas exceeding the threshold of $\mathrm{p}<0.001$ uncorrected at the voxel level and belonging to a cluster of activation with an extent of at least 10 voxels are displayed.

$\mathrm{x}, \mathrm{y}, \mathrm{z}$ : location in MNI coordinates.

$\mathrm{BA}=\operatorname{Brodmann}$ area; $(\mathrm{Z})=\mathrm{Z}$-score; $\mathrm{L}=$ left $\mathrm{R}=$ right.

\section{Regression analysis}

The brain regions in which the scores on the temperament dimension were significantly correlated with the BOLD responses of $\mathrm{BN}$ patients are shown in Table 3. The NS score was negatively correlated with the activations in the left inferior frontal gyrus (IFC) (BA47) (Figure 3a), the right superior frontal gyrus (SFC) (BA8) and the insula (BA 13). The HA 


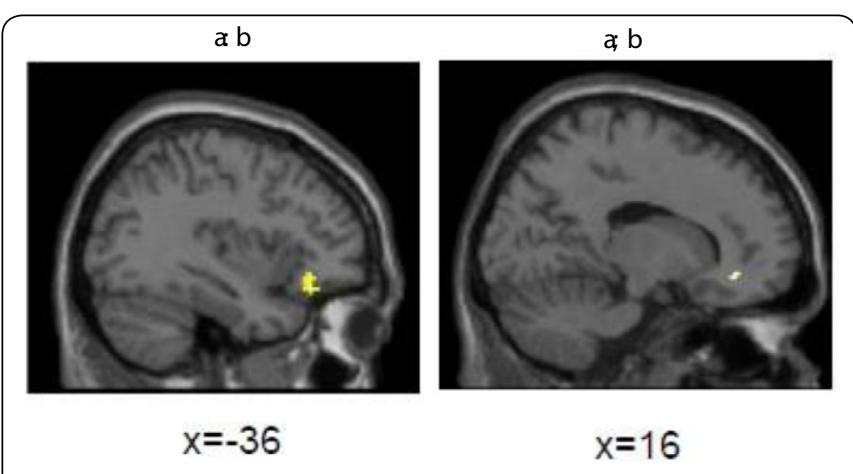

Figure 3: Brain activations during the task in the $\mathrm{BN}$ patients. (a) Negative correlation with the NS score. (b) Positive correlation with the HA score.

Table 3: Areas with activations that significantly correlated with TCI scores in $\mathrm{BN}$ patients.

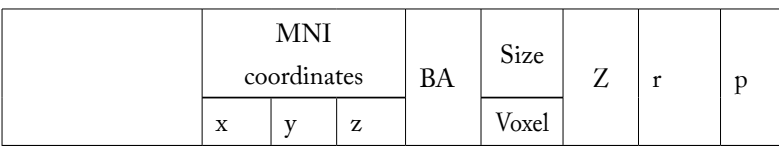

\section{TCI score}

Positive correlation with NS

No significant results

Negative correlation with NS

\begin{tabular}{|l|c|c|c|c|c|c|c|c|}
\hline $\begin{array}{l}\text { L inferior } \\
\text { frontal gyrus }\end{array}$ & -36 & 32 & -14 & 47 & 36 & 3.88 & -0.77 & $<0.001$ \\
\hline $\begin{array}{l}\mathrm{R} \text { superior } \\
\text { frontal gyrus }\end{array}$ & 10 & 42 & 54 & 8 & 11 & 3.75 & -0.72 & 0.002 \\
\hline $\mathrm{R}$ insula & 40 & -10 & 14 & 13 & 15 & 3.52 & -0.66 & 0.006 \\
\hline $\mathrm{L}$ insula & -42 & -40 & 16 & 13 & 8 & 3.31 & -0.69 & 0.004 \\
\hline
\end{tabular}

Positive correlation with HA

\begin{tabular}{|l|c|c|c|c|c|c|c|c|}
\hline $\begin{array}{l}\text { L inferior } \\
\text { parietal lobule }\end{array}$ & -64 & -42 & 28 & 40 & 29 & 3.65 & 0.75 & $<0.001$ \\
\hline $\begin{array}{l}\text { L superior } \\
\text { temporal gyrus }\end{array}$ & -58 & -62 & 20 & 39 & 8 & 3.56 & 0.62 & 0.01 \\
\hline $\begin{array}{l}\text { R anterior } \\
\text { cingulate gyrus }\end{array}$ & 16 & 38 & -10 & 10 & 1 & 3.03 & 0.61 & 0.01 \\
\hline $\begin{array}{l}\text { L anterior } \\
\text { cingulate gyrus }\end{array}$ & -2 & -18 & 30 & 23 & 1 & 2.99 & 0.58 & 0.02 \\
\hline
\end{tabular}

Negative correlation with HA

No significant results

Positive correlation with $\mathrm{RD}$

No significant results

Negative correlation with $\mathrm{RD}$

\begin{tabular}{|l|c|c|c|c|c|c|c|c|}
\hline $\begin{array}{l}\text { L superior } \\
\text { parietal lobule }\end{array}$ & -18 & -60 & 52 & 7 & 23 & 3.46 & -0.68 & 0.004 \\
\hline $\begin{array}{l}\text { L superior } \\
\text { frontal gyrus }\end{array}$ & -22 & 30 & 48 & 8 & 6 & 3.31 & -0.68 & 0.004 \\
\hline
\end{tabular}

Positive correlation with PT

\begin{tabular}{|l|c|c|c|c|c|c|c|c|}
$\mathrm{R}$ middle & 32 & 44 & 30 & $9 / 10$ & 8 & 3.49 & 0.79 & $<0.001$ \\
\hline
\end{tabular}
frontal gyrus

Negative correlation with PT

No significant results

$\mathrm{x}, \mathrm{y}, \mathrm{z}$ : location in MNI coordinates.

$\mathrm{TCI}=$ Temperament and Character Inventory; BA= Brodmann area; $(\mathrm{Z})=$ $\mathrm{Z}$-score; $\mathrm{L}=$ left; $\mathrm{R}$ = right. $\mathrm{NS}$ = novelty seeking; $\mathrm{HA}$ = harm avoidance; $\mathrm{RD}=$ reward dependence; $\mathrm{PT}=$ persistence. score was positively correlated with the activations in the ACC (BA 24, 32) (Figure 3b), the left inferior parietal lobule (IPL) (BA 40) and the left superior temporal gyrus (BA 39). The RD score was negatively correlated with the activations in the left superior parietal lobule (BA7) and the left SFC (BA8). The PT score was positively correlated with the activations in the right middle frontal gyrus (BA 9/10). Neither participant age nor BMI was correlated with the BOLD responses observed in any brain region. There was no significant correlation between the brain activation and the subjective ratings of the words.

\section{Discussion}

We investigated the relationships between temperamental predispositions and brain responses in $\mathrm{BN}$ patients during the processing of stressful word stimuli related to interpersonal relationships. The activations of the $\mathrm{mPFC}$ and the left ACC were significantly increased in the task condition compared to the control condition. All participants rated the interpersonal relationship words as significantly more unpleasant than the neutral words; this suggests that the task manipulation of emotionality was successful. The activation of the ACC was positively correlated with the HA score. The activations in the left IFC and the insula were negatively correlated with NS score. To our knowledge, this is the first study to investigate the relationships between temperament traits and brain responses to interpersonal relationship stimuli in $\mathrm{BN}$ patients.

We revealed that the activation of the ACC was significantly positively correlated with the HA score. The activation of the ACC was significantly greater in the $\mathrm{BN}$ patients than in the control subjects. HA reflects the intensity of responses to signals of aversive stimuli and is thus related to learning to inhibit behavior to avoid punishment and frustration. Some neuroimaging studies have suggested that the ACC is a pivotal component of the brain networks that direct various emotional and cognitive functions $[34,35]$. The ACC serves to modulate various internal emotional responses [36]. The ACC is also considered to be an integral component of awareness and insight [34, 35, 37]. Eisenberger et al. [38] suggested that the ACC is involved in social pain. An fMRI experiment revealed that a significant increase in ACC activity occurs when participants are socially isolated during a virtual game of catch [38]. Social pain involves unpleasant affects that are experienced upon social injury, specifically when social relationships are threatened, damaged, or lost [39]. The $\mathrm{BN}$ patients may have tended to feel more socially isolated and stressed during the perception of stressful word stimuli in this study. We suggest that greater activation of the ACC in response to stressful stimuli might also play a crucial role in the emotional processing impairments that are often observed in $\mathrm{BN}$ patients when interpersonal relationships are damaged.

Moreover, the activations of the left IFC, the insula and the SFC were negatively correlated with the NS scores of the $\mathrm{BN}$ patients. Individuals with high NS scores are characterized as impulsive or excitable. High NS represents a specific genetic predisposition to binge-purging behaviors when other predisposing factors to ED coexist [11-13]. The left IFC has been implicated in self-regulatory control and particularly 
inhibitory control [40]. The insula has been implicated in affective processing, including emotional and interoceptive awareness and self-regulation [41]. Insular dysfunction is associated with increased threat perception [42]. The activity of the SFC was negatively correlated with the NS score and the RD score. The SFC is also involved in self-awareness [43]. BN patients are thought to belong to the impulsive pole of the spectrum, but no significant differences in the NS scores between the BN patients and the control subjects were observed in this study. Understanding the impulsive aspect of BN may help guide treatments or allow for improved outcome prediction [44]. The uncontrolled overeating exhibited by $\mathrm{BN}$ patients seems to suggest the presence of pathological impulsiveness and a lack of inhibitory control. Therefore, one possible interpretation of the reduced activations of the IFC, insula and SFC in response to stressful stimuli observed in BN patients is that the presentation of the stressful words elicited the impulsive aspect of $\mathrm{BN}$ in these patients.

We found a significant activation in the mPFC and left $\mathrm{ACC}$ in the $\mathrm{BN}$ patients during the task, but these areas did not show significant activation among the control subjects. The $\mathrm{mPFC}$ is related to general emotional processing and evaluative judgment $[45,46]$. Somerville et al. [47] reported that healthy people with low self-esteem showed modulation of responses in their ventral $\mathrm{ACC}$ and $\mathrm{mPFC}$ in response to social feedback but that people with high self-esteem showed no changes in this region in response to feedback. Onoda et al. [48] reported that people with lower self-esteem show increased social pain and dorsal ACC activity than do people with higher self-esteem, and the observed dorsal ACC activity was associated with mPFC activity. McAdams and Krawczyk [49] suggested that neural responses to social feedback in the ACC and mPFC might provide a biological mechanism that connects social cognitive responses and self-esteem with eating pathology. Low self-esteem has been related to the onset of bulimic symptoms [50]. Therefore, one possible interpretation of the $\mathrm{MPFC}$ and ACC activations during the task may be associated with the subjects' low self-esteem, and this process may be associated with the onset of binge eating in $\mathrm{BN}$ patients.

It is important to note that our study has some limitations. First, the nature of our sample limits the generalizability of our findings. Although the majority of the included patients had a chronic disease course and had been ill for many years, the duration of BN did not significantly affect any of the brain activations observed in this study. Second, Although $\mathrm{BN}$ patients fulfilled the DSM-IV diagnostic criteria for $\mathrm{BN}$, the current version is DSM-V. Also, we used SPM5 for the image processing and statistical analyses in this study. There are more recent versions of SPM. Further studies that consider these points are needed. Third, we did not consider the multiple other language related issues before settling on a test set. Further studies are also needed to consider this. Fourth, although BN patients are thought to belong to the impulsive pole of the spectrum, there was no significant difference in the NS scores between our BN patients and the control subjects in this study. Further confirmation of our results and further studies of personality traits in $\mathrm{BN}$ that use instruments other than the TCI are required to make our results more useful for understanding BN. Finally, because our sample size is small, our results may not be specific to BN. This study did not consider other subgroups of ED or the regression analysis in the control subjects. Further studies that consider this point are needed.

\section{Conclusion}

Our study indicated the relationship between functional responses to interpersonal relationship stress and temperamental predisposition in $\mathrm{BN}$ patients. We suggest that these functional abnormalities may also play a crucial role in the emotional processing impairments and difficulties in adapting to stressful situations in $\mathrm{BN}$ patients.

\section{Acknowledgments}

This study was partially supported by the Strategic Research Program for Brain Sciences, a Grant-in-Aid for Scientific Research on Innovative Areas and a Grant-in-Aid for Young Scientists.

\section{References}

1. Peterson CB, Thuras P, Ackard DM, Mitchell JE, Berg K, et al. 2010. Personality dimensions in bulimia nervosa, binge eating disorder, and obesity. Compr Psychiatry 51(1): 31-36. doi: 10.1016/j. comppsych.2009.03.003

2. McEwen BS. 2007. Stress, definitions and concepts of. In: Fink G (eds) Encyclopedia of Stress. Academic Press, CA, USA, pp 508-509. doi: 10.1016/B978-012373947-6.00364-0

3. Waller G, Kennerley H, Ohanian V, Riso LP, du Toit PT, et al. 2007. Schema-focused cognitive behavior therapy with eating disorders. In: Riso LP, du Toit PL, Stein DJ, Young JE (eds) Cognitive schemas and core beliefs in psychiatric disorders: A scientist practioners' guide. American Psychological Association, Washington, DC, USA, pp 139175. doi: 10.1037/11561-007

4. Pringle A, Ashworth F, Harmer CJ, Norbury R, Cooper MJ. 2011. Neural correlates of the processing of self-referent emotional information in bulimia nervosa. Neuropsychologia 49(12): 3272-3278. doi: 10.1016/j.neuropsychologia.2011.07.032

5. Cassin SE, von Ranson KM. 2005. Personality and eating disorders: A decade in review. Clin Psychol Rev 25(7): 895-916. doi: 10.1016/j. cpr.2005.04.012

6. Wagner AN, Barbarich-Marsteller NC, Frank GK, Bailer UF, Wonderlich SA, et al. 2006. Personality traits after recovery from eating disorders: do subtypes differ? Int J Eat Disord 39(4): 276-284. doi: 10.1002/eat.20251

7. Cloninger CR, Svrakic DM, Przybeck TR. 1993. A psychobiological model of temperament and character. Arch Gen Psychiatry 50(12): 975990. doi: 10.1001/archpsyc.1993.01820240059008

8. Harrison A, O'Brien N, Lopez C, Treasure J. 2010. Sensitivity to reward and punishment in eating disorders. Psychiatry Res 177(1-2): 1-11. doi: 10.1016/j.psychres.2009.06.010

9. Cloninger CR, Svrakic DM. 2000. Personality Disorders. In: BJ. Sadock BJ, Sadock VA, Ruiz P (eds) Kaplan and Sadock's comprehensive textbook of psychiatry. Wolters Kluwer Health/Lippincott Williams \& Wilkins, USA, pp 1723-1764.

10. Fassino S, Abbate-Daga G, Amianto F, Leombruni P, Boggio S, et al. 2002. Temperament and character profile of eating disorders: A controlled study with the Temperament and Character Inventory. Int $J$ Eat Disord 32(4): 412-425. doi: 10.1002/eat.10099 
11. Klump KL, Bulik CM, Pollice C, Halmi KA, Fichter MM, et al. 2000. Temperament and character in women with anorexia nervosa. J Nerv Ment Dis 188(9): 559-567.

12. Bulik CM, Sullivan PF, Joyce PR, Carter FA. 1995. Temperament, character, and personality disorder in bulimia nervosa.J Nerv Ment Dis 183(9): 593-598.

13. Bulik CM, Sullivan PF, Weltzin TE, Kaye WH. 1995 Temperament in eating disorders. Int $J$ Eat Disord 17(3): 251-261. doi: 10.1002/1098-108X(199504)17:3<251::AIDEAT2260170306>3.0.CO;2-V

14. Comings DE, Gade-Andavolu R, Gonzalez N, Wu S, Muhleman D, et al. 2000. A multivariate analysis of 59 candidate genes in personality traits: the temperament and character inventory. Clin Genet 58(5): 375385. doi: 10.1034/j.1399-0004.2000.580508.x

15. Tellegen A, Lykken DT, Bouchard TJ Jr, Wilcox KJ, Segal NL, et al. 1988. Personality similarity in twins reared apart and together.JPers Soc Psychol 54(6): 1031-1039. doi: 10.1037/0022-3514.54.6.1031

16. Gardini S, Cloninger CR, Venneri A. 2009. Individual differences in personality traits reflect structural variance in specific brain regions. Brain Res Bull 79(5): 265-270. doi: 10.1016/j.brainresbull.2009.03.005

17. Amianto F, Siccardi S, Abbate-Daga G, Marech L, Barosio M, et al. 2012. Does anger mediate between personality and eating symptoms in bulimia nervosa. Psychiatry Res 200(2-3): 502-512. doi: 10.1016/j. psychres.2012.07.036

18. Youn T, Lyoo IK, Kim JK, Park HJ, Ha KS, et al. 2002. Relationship between personality trait and regional cerebral glucose metabolism assessed with positron emission tomography. Biol Psychology 60(2-3): 109-120. doi: 10.1016/S0301-0511(02)00047-9

19. Mobbs D, Hagan CC, Azim E, Menon V, Reiss AL. 2005. Personality predicts activity in reward and emotional regions associated with humor. Proc Natl Acad Sci USA 102(45): 16502-16506. doi: 10.1073/ pnas.0408457102

20. Marsh R, Steinglass JE, Gerber AJ, O'Leary KG, Wang Z, et al. 2009. Deficient activity in the neural systems that mediate self-regulatory control in bulimia nervosa. Arch Gen Psychiatry 66(1): 51-63. doi 10.1001/archgenpsychiatry.2008.504

21. Miyake Y, Okamoto Y, Onoda K, Shirao N, Okamoto Y, et al. 2010. Neural processing of negative word stimuli concerning body image in patients with eating disorders: An fMRI study. Neuroimage 50(3): 13331339. doi: 10.1016/j.neuroimage.2009.12.095

22. Joos AA, Gille M, Hartmann A, Unterbrink T, Wetzler-Burmeister E, et al. 2012. Emotional perception in patients with eating disorders in comparison with depressed patients. Eur Eat Disord Rev 20(6): 468475. doi: 10.1002/erv.1132

23. Lock J, Garrett A, Beenhakker J, Reiss AL. 2011. Aberrant brain activation during a response inhibition task in adolescent eating disorder subtypes. Am J Psychiatry 168(1): 55-64. doi: 10.1176/appi. ajp.2010.10010056

24. First MB, Gibbon M, Spitzer RL, Williams JB, Benjamin LS. 1997. Structured Clinical Interview for DSM-IV Axis II Personality Disorders (SCID-II). American Psychiatric Press, Washington DC, USA.

25. First MB, Spitzer RL, Gibbon M, Williams JB. 1997. Structured Clinical Interview for DSM-IV Axis I Disorders-Clinician Version (SCID-I: CV). American Psychiatric Press, Washington DC, USA.

26. Miyake Y, Okamoto Y, Onoda K, Shirao N, Okamoto Y, et al. 2012. Brain activation during the perception of stressful word stimuli concerning interpersonal relationships in anorexia nervosa patients with high degrees of alexithymia in an fMRI paradigm. Psychiatry Res 201(2): 113-119. doi: 10.1016/j.pscychresns.2011.07.014

27. Oldfield RC. 1971. The assessment and analysis of handedness: the Edinburgh inventory. Neuropsychologia 9(1): 97-113. doi: 10.1016/00283932(71)90067-4

28. Kijima N, Saito R, Takeuchi M, Yoshino S, Ono Y, et al. 1996.
Cloninger's seven-factor model of temperament and character and Japanese version of Temperament and Character Inventory (TCI). Arch Psychiatr Diagn Clin Eval 7(3): 379-399. (in Japanese)

29. Garner DM.1991.Eating Disorder Inventory-2 (EDI-2). Psychological Assessment Resources, Odessa FL, USA.

30. Shirao N, Okamoto Y, Okada G, Ueda K, Yamawaki S. 2005. Gender differences in brain activity toward unpleasant linguistic stimuli concerning interpersonal relationships: an fMRI study. Eur Arch Psychiatry Clin Neurosci 255(5): 327-333. doi: 10.1007/s00406-0050566-x

31. Toglia MP, Battig WF. 1978. Handbook of Semantic Word Norms. Lawrence Erlbaum, Hillsdale NJ, USA

32. Shirao N, Okamoto Y, Okamoto Y, Otagaki Y, Morinobu S, et al. 2003. Ratings of negative body image words, negative emotion words and neutral words by eating disorder patients and healthy subjects. Brain Sci Ment Disord 14: 141-147.

33. Friston KJ,Holmes AP,Worsley KJ.1999. How many subjects constitute a study? Neuroimage 10(1): 1-5. doi: 10.1006/nimg.1999.0439

34. Devinsky O, Morrell MJ, Vogt BA. 1995. Contributions of anterior cingulated cortex to behavior. Brain 118(1): 279-306. doi: 10.1093/ brain/118.1.279 279-306

35. Vogt BA, Finch DM, Olson CR. 1992. Functional heterogeneity in cingulated cortex: the anterior executive and posterior evaluative regions. Cereb Cortex 2(6): 435-443. doi: 10.1093/cercor/2.6.435-a

36. Pujol J, Lopez A, Deus J, Cardoner N, Vallejo J, et al. 2002. Anatomical variability of the anterior cingulate gyrus and basic dimensions of human personality. Neuroimage 15(4): 847-855. doi: 10.1006/nimg.2001.1004

37. Badgaiyan RD, Posner MI. 1998. Mapping the cingulate cortex in response selection and monitoring. Neuroimage 7(3): 255-260. doi: 10.1006/nimg.1998.0326

38. Eisenberger NI, Lieberman MD, Williams KD. 2003. Does rejection hurt? An FMRI study of social exclusion. Science 302(5643): 290-292. doi: 10.1126/science.1089134

39. Eisenberger NI, Lieberman MD. 2004. Why rejection hurts: a common neural alarm system for physical and social pain. Trends Cogn Sci 8(7): 294-300. doi: 10.1016/j.tics.2004.05.010

40. Swick D, Ashley V, Turken AU. 2008. Left inferior frontal gyrus is critical for response inhibition. BMCNeurosci 9: 102. doi: 10.1186/14712202-9-102

41. Lawrence EJ, Su L, Barker GJ, Medford N, Dalton J, et al. 2014. Selfregulation of the anterior insula: Reinforcement learning using realtime fMRI neurofeedback. Neuroimage 88: 113-124. doi: 10.1016/j. neuroimage.2013.10.069

42. Kumari V, Fannon D, Peters ER, Ffytche DH, Sumich AL, et al. 2011. Neural changes following cognitive behaviour therapy for psychosis: a longitudinal study. Brain 134(Pt 8): 2396-2407. doi: 10.1093/brain/ awr154

43. Goldberg I, Harel M, Malach R. 2006. When the brain loses its self: prefrontal inactivation during sensorimotor processing. Neuron 50(2): 329-339. doi: 10.1016/j.neuron.2006.03.015

44. Raymond NC, Eckert ED, Hamalainen M, Evanson D, Thuras PD, et al. 1999. A preliminary report on pain thresholds in bulimia nervosa during a bulimic episode. Compr Psychiatry 40(3): 229-233. doi: 10.1016/S0010-440X(99)90009-3

45. Elliott R, Rubinsztein JS, Sahakian BJ, Dolan RJ. 2002. The neural basis of moodcongruent processing biases in depression. Arch Gen Psychiatry 59(7): 597-604. doi: 10.1001/archpsyc.59.7.597

46. Zysset S, Huber O, Ferstl E, von Cramon DY. 2002. The anterior frontomedian cortex and evaluative judgment: an fMRI study. Neuroimage 15(4): 983-991. doi: 10.1006/nimg.2001.1008

47. Somerville LH, Kelley WM, Heatherton TF. 2010. Self-esteem modulates medial prefrontal cortical responses to evaluative social feedback. Cereb Cortex 20(12): 3005-3013. doi: 10.1093/cercor/bhq049 
48. Onoda K, Okamoto Y, Nakashima K, Nittono H, Yoshimura S, et al. 2010. Does low self-esteem enhance social pain? The relationship between trait self-esteem and anterior cingulated cortex activation induced by ostracism. Soc Cogn Affect Neurosci 5(4): 385-391. doi: $10.1093 / \mathrm{scan} / \mathrm{nsq002}$

49. McAdams CJ, Krawczyk DC. 2013. Neural responses during social and self-knowledge task in bulimia nervosa. Front Psychiatry 4: 103. doi: 10.3389/fpsyt.2013.00103

50. Vohs KD, Bardone AM, Joiner TE Jr, Abramson LY, Heatherton TF. 1999. Perfectionism, perceived weight status, and self-esteem interact to predict bulimic symptoms: a model of bulimic symptom development. J Abnorm Psychol 108(4): 695-700. doi: 10.1037/0021-843X.108.4.695 